DNA Libraryof Life, research article

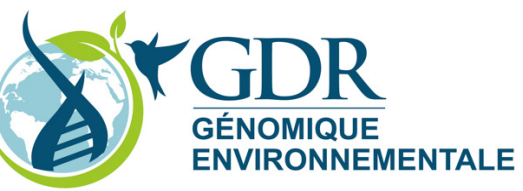

urn:1sid:zoobank.org:pub:59ADAF1D-4704-49A2-9467-ADE8813F75FA

\title{
Molecular phylogeny of Blaberidae (Dictyoptera, Blattodea), with implications for taxonomy and evolutionary scenarios
}

\author{
Frédéric LEGENDRE ${ }^{1, *}$, Philippe GRANDCOLAS ${ }^{2} \&$ France THOUZÉ $^{3}$ \\ Institut de Systématique, Évolution, Biodiversité ISYEB - UMR 7205 - MNHN \\ CNRS UPMC EPHE, Muséum national d'Histoire naturelle, \\ Sorbonne Universités, 57 rue Cuvier, CP 50, 75005 Paris, France. \\ *Corresponding author: legendre@mnhn.fr \\ ${ }^{2}$ Email: pg@mnhn.fr \\ ${ }^{3}$ Email: francethouze@gmail.com \\ ${ }^{1}$ urn:lsid:zoobank.org:author:8B1163C9-338E-425A-9107-C185D4AB415F \\ ${ }^{2}$ urn:Isid:zoobank.org:author:FCCF6C9C-F929-453E-989B-C5BB4B04B54A \\ ${ }^{3}$ urn:1sid:zoobank.org:author:6692EB45-5E95-41AB-BB1F-59B3154B3402
}

\begin{abstract}
In the present "tree-thinking" period, relying on accurate phylogenetic hypotheses is of paramount importance for biologists interested in an evolutionary perspective. In the Blaberidae cockroaches, a well-defined monophyletic family comprising several model species, no such phylogenetic tree is available despite several earlier contributions. Here, using six molecular markers $(12 \mathrm{~S}, 16 \mathrm{~S}$, $18 \mathrm{~S}, 28 \mathrm{~S}$, COI and COII), we investigate the relationships of Blaberidae and compare our results with the traditional morphology-based classification. This resulted in a broad spectrum of situations, from congruent and well-supported hypotheses (e.g., the monophyly of Blaberidae, Oxyhaloinae and (Geoscapheiinae + Panesthiinae)) to incongruent and weakly supported results (e.g., polyphyly of Perisphaerinae). We emphasize that interesting and contrasted situations lie between the two extremities of this spectrum, especially concerning the genera Thanatophyllum Grandcolas, 1991, Phoetalia Stål, 1874, Laxta Walker, 1868 and Pronauphoeta Shelford, 1909. We also discuss the phylogenetic position of two incertae sedis genera (Eustegasta Gerstaecker, 1883 and Gynopeltis Gerstaecker, 1869). We conclude that in-depth signal analyses should be performed to better understand molecular evolution and its consequence on tree reconstruction for this group. As for phylogenetic relationships per se, new markers should be searched for, especially to decipher deeper relationships in Blaberidae.
\end{abstract}

Keywords. Biogeography, incongruence, genitalia, morphology, phylogenetic signal.

Legendre F., Grandcolas P. \& Thouzé F. 2017. Molecular phylogeny of Blaberidae (Dictyoptera, Blattodea), with implications for taxonomy and evolutionary scenarios. European Journal of Taxonomy 291: 1-13. https://doi. org/10.5852/ejt.2017.291

\section{Introduction}

We are presently experiencing what has been called a "tree-thinking biology" era (Grandcolas et al. 1994; O’Hara 1997; Baum et al. 2005; Gregory 2008; Omland et al. 2008; Baum \& Smith 2013; Losos 
et al. 2013). Myriad phylogenies are produced every year (Parr et al. 2012) and these hypotheses serve to investigate diverse evolutionary questions or to revise classifications. Even though these numerous hypotheses might be contradictory and thus bewildering (Chiapella et al. 2014), they are essential for present and future studies, especially when they involve model organisms from various disciplines.

Blaberid cockroaches comprise model species in research about biomimetics (e.g., Nelson et al. 1997), physiology (Li 2007), sociality (Costa 2006; Pellens et al. 2007) or reproductive behavior (Roth \&Willis 1954; Banerjee et al. 2016). These fields of research would benefit from a clear phylogenetic hypothesis or a phylogeny-derived robust classification. Yet, such a phylogeny is still lacking despite several relevant contributions since Saussure (1864) erected the Blaberidae family.

McKittrick (1964) was the first to define this family as we consider it today. She distinguished three complexes which she named blaberoid, epilamproid and panchloroid, but without performing any formal phylogenetic analysis. A cladistic analysis of her data, however, revealed that her blaberoid and panchloroid complexes were not monophyletic (Legendre 2007). Later, cockroach systematists identified several morphological synapomorphies supporting the monophyly of Blaberidae (Grandcolas 1996; Klass \& Meier 2006; brood sac underneath the female genitalia, sclerite R3v small, first vein of vannus with many basal rami, tracheation very dense and tracheae vesicle-shaped, presence of a muscle connecting sclerite L2 and pouch lve). Monophyly has also repeatedly been found with molecular data as well (Maekawa et al. 2003; Inward 2007; Pellens et al. 2007; Djernaes et al. 2012; Legendre et al. 2014, 2015).

Within Blaberidae, however, the phylogenetic relationships remain controversial, despite early morphological studies (e.g., Grandcolas 1993, 1997). The only largely supported results are the close relationships between Zetoborinae and Blaberinae on the one hand, and Panesthiinae and Geoscapheinae on the other. The position of Panchlorinae as the first diverging lineage within the family also seems to be consistently found lately even though often based on a limited taxon sample (Legendre et al. 2014, 2015). The phylogenetic positions of the seven remaining subfamilies still need to be investigated further, as do the phylogenetic positions of 24 incertae sedis genera (according to the Blattodea Species File, BSF; Beccaloni 2014).

The taxonomy of cockroaches relies heavily on morphological characters, especially those of the genitalia. Insect taxonomists often use genitalia for species identification as well as for classification, proposing synapomorphies for diverse subfamilies and genera (e.g., Grandcolas 1993, 1994, 1996, 1997; Roth 2003; Klass \& Meier 2006). The current classification systems of cockroaches are thus based mainly on morphological characters (Roth 2003). However, like any set of characters, morphological characters benefit from completion with other kinds of data, as already shown when combining molecular and behavioral characters for instance (Legendre et al. 2014).

In terms of geographical range, Blaberidae have a pantropical distribution. Some subfamilies are restricted to one continent, while others encompass several. Blaberinae and Zetoborinae are endemic to America (mainly South America), Gyninae and Oxyhaloinae are endemic to Africa, Geoscapheinae is endemic to Australia, and Paranauphoetinae is endemic to Asia. Panchlorinae is found in America and Africa, Pycnoscelinae is found in Asia and South America, while Diplopterinae and Panesthiinae are found in Asia and Australasia. Perisphaerinae is found in Africa, Asia and Australasia, and Epilamprinae is found in America, Africa, Asia and Australasia (Princis 1964; Beccaloni 2014).

In this paper, we investigate the phylogenetic relationships in blaberid cockroaches using six molecular markers. We then compare our results to the largely pre- or semi-phylogenetic current morphology-based classification of this family as presented in the CSF (Beccaloni 2014). We underline the differences found and interpret them in terms of potential morphological evolution and biogeography. We also propose future directions to improve our knowledge of the phylogenetics of Blaberidae. 


\section{Material and methods}

\section{Taxonomic and character sampling}

We sampled 136 taxa, 128 of them belonging to 11 out of the 12 currently distinguished subfamilies of Blaberidae (according to the BSF; Beccaloni 2014): 18 Blaberinae (12 genera out of 23 genera recognized in the BSF, i.e. $\sim 52 \%$ ), one Diplopterinae (one genus, 100\%), 26 Epilamprinae (at least 11 genera, $\sim 24 \%$ ), 10 Geoscapheinae (four genera, 100\%), five Gyninae (one genus, 20\%), 13 Oxyhaloinae (11 genera, $\sim 65 \%$ ), three Panchlorinae (one genus, 20\%), 23 Panesthiinae (five genera, $\sim 71 \%$ ), 18 Perisphaerinae (at least seven genera, $\sim 37 \%$ ), two Pycnoscelinae (one genus, $\sim 33 \%$ ), and nine Zetoborinae (eight genera, $57 \%$ ). We also included five specimens belonging to the incertae sedis genera Eustegasta Gerstaecker, 1883 and Gynopeltis Gerstaecker, 1869. Outgroup taxa comprise one Ectobiidae (Paratropes sp. 1), one Corydiidae (Therea petiveriana Linnaeus, 1758) and one Blattidae (Blatta orientalis Linnaeus, 1758) as the rooting outgroup taxon. Among Ectobiidae, all subfamilies have been postulated as being the sister group of Blaberidae, including Pseudophyllodromiinae (Grandcolas 1996; Inward et al. 2007; Pellens et al. 2007; Djernaes et al. 2012; Legendre et al. 2015). At first, we included several species of Pseudophyllodromiinae (Anisopygia sp., Asemoblattana sp., Euphyllodromia sp., Latiblattella sp. 3) but we then discarded them because of their artifactual position within Blaberidae (among Epilamprinae, data not shown). All the species of Pseudophyllodromiinae sequenced so far show highly modified sequences, which results in high percentages of divergence with ingroup species and may cause artifacts in tree reconstruction such as long branch attraction (Wheeler 1990; Bergsten 2005; Legendre et al. 2015). Also a couple of additional species of Blattellinae were used as outgroup taxa in preliminary analyses (Ischnoptera sp. and Xestoblatta sp.), but were not kept because of their missing data, which might alter tree reconstruction (e.g., Lemmon et al. 2013; Roure et al. 2013). Whatever the outgroup combinations used in our preliminary analyses, the supported results presented here were always retrieved.

We used six molecular markers to reconstruct blaberid phylogenetic relationships: 12S rRNA ( 440 bp), $16 \mathrm{~S}$ rRNA ( $\sim 40 \mathrm{bp}), 18 \mathrm{~S}$ rRNA ( $1900 \mathrm{bp}), 28 \mathrm{~S}$ rRNA ( 2350 bp), cytochrome oxidase subunit I (COI, $1179 \mathrm{bp}$ ) and cytochrome oxidase subunit II (COII, $671 \mathrm{bp})$. Primers and molecular techniques were described in Legendre et al. (2008). We provided 175 new sequences, which were deposited in GenBank with the following accession numbers: KY497575-KY497749. In average, taxa were documented for ca $4000 \mathrm{bp}$ (for a total alignment of $6991 \mathrm{bp}$ ). We sampled 92\% of the taxa for 12S, 57\% for $16 \mathrm{~S}, 95 \%$ for $18 \mathrm{~S}, 76 \%$ for $28 \mathrm{~S}, 38 \%$ for COI and $78 \%$ for COII. The Supplementary file shows the details of the completion of our dataset.

\section{Phylogenetic analyses}

All sequences were blasted prior to any analysis to check for potential contamination. Then, we computed alignments using MUSCLE (Edgar 2004) as implemented in Seaview v. 4 (Gouy et al. 2010). For 28S, alignments were performed separately for each fragment and then concatenated, whereas fragments were concatenated before alignment for $18 \mathrm{~S}$. The $28 \mathrm{~S}$ fragments do not or hardly overlap so that they could not be aligned altogether. For each marker, the proposed alignments were sometimes dubious, especially in the terminal regions because of fragments that were not always congruent in coverage. We corrected these problems by refining the alignment manually. Morever, we ensured that alignments respect the codon protein reading frame for COI and COII. Once we obtained separate alignments for the six markers, we used SequenceMatrix v. 1.7 .8 (Vaidya et al. 2011) to produce the full dataset composed of $6991 \mathrm{bp}$.

We performed separate and combined analyses in a probabilistic framework. For separate analyses, we selected the best model that does not mix I (proportion of invariant sites) and G (heterogeneity of substitution rates) using jMrModeltest v. 2.1.3 (Darriba et al. 2012) with the AICc criterion. 
For combined analyses, we used Partitionfinder v. 1.1.1 (Lanfear et al. 2012; options: branchlengths= linked, model_selection $=A I C c$ and search $=$ greedy) to select the best partition strategy among models supported by MrBayes. The best partitioning strategy involved nine partitions: one partition with a GTR + G model for each non-protein-coding marker; four distinct partitions for the first two positions of COI and COII with a GTR + G model; and a common partition for the third positions of COI and COII, also with a GTR $+\mathrm{G}$ model.

In Maximum Likelihood (ML), we used RAxML v. 8.2.4 (Stamatakis 2014) to reconstruct phylogenetic hypotheses, whereas we used MrBayes v. 3.1.2 (Ronquist \& Huelsenbeck 2003) in Bayesian Inferences (BI). ML analyses were performed using the rapid hill-climbing algorithm for 500 replicates. We then computed 500 bootstrap replicates. In BI, we launched two runs of four chains each until the average deviation of split frequencies reached a value inferior to 0.01 (options: stoprule $=y e s$, stopval $=0.01$ ). We then assessed convergence using Tracer v. 1.6 (Rambaut et al. 2014), checking that ESS values all exceed 200.

\section{Results}

The best tree from the ML combined analysis is shown in Fig. 1 and is very similar to the tree reconstructed in Bayesian Inference (note that convergence diagnostics and ESS values were satisfying, except for the ESS values of the rate multiplier parameters). Blaberidae were monophyletic with a moderate bootstrap support and a maximal posterior probability $(\mathrm{BS}=94, \mathrm{PP}=1)$. Panchlorinae, Gyninae, Pycnoscelinae and Oxyhaloinae were monophyletic (BS/PP $=100 / 1,99 / 1,90 / 0.9$ and 50/0.93, respectively), while Blaberinae, Epilamprinae, Perisphaerinae and Zetoborinae were polyphyletic. The group (Panesthiinae + Geoscapheinae) was monophyletic $(\mathrm{BS}=99, \mathrm{PP}=1)$, with Australian Panesthia nested within Geoscapheinae.

Overall, this tree showed very weak support values for deeper relationships within Blaberidae. Nevertheless, some clades with geographic congruence were retrieved. African Perisphaerinae, Asian Perisphaerinae, African Epilamprinae and Asian-Oceanian Epilamprinae (except Rhabdoblatta cf. circumdata from Singapore) were monophyletic with high to moderate support values (BS/PP $=100 / 1$, $100 / 0.96,100 / 1$ and $81 / 0.9$, respectively), and a Neotropical clade composed of the Blaberinae and most of the Zetoborinae was found ( $\mathrm{BS} / \mathrm{PP}=43 / 0.86$; see exceptions below).

The phylogenetic position of Phoetalia pallida (Brunner von Wattenwyl, 1865) (Blaberinae) as sister species to Schultesia lampyridiformis Roth, 1973 (Zetoborinae) was highly supported (BS/PP = 100/1) and found in almost all the analyses performed (Fig. 2). Three other Blaberinae species (Lucihormetica subcincta (Walker, 1868), Hormetica sp. and Blaptica sp.) were found closer to most species of Zetoborinae than to other Blaberinae. Parasphaeria boleiriana Grandcolas \& Pellens, 2002 (Zetoborinae) branched outside of the Neotropical clade composed of the Blaberinae and most of the Zetoborinae, but its phylogenetic position was unsupported (BS/ $\mathrm{PP}=11 / 0.81$ ), whereas the position of Thanatophyllum akinetum Grandcolas, 1991 (Zetoborinae) as sister group to some Neotropical Epilamprinae was highly supported (BS/PP = 99/1) and found in half of the separate analyses (Fig. 2). Within Oxyhaloinae, the Nauphoetini were monophyletic, whereas the Gromphadorhini were monophyletic only if the incertae sedis genera Brachynauphoeta van Herrewege, 1975 and Heminauphoeta Saussure, 1891 are taken into account. The incertae sedis Oxyhaloinae genus Pronauphoeta was sister group to all other species of Oxyhaloinae sampled here $(\mathrm{BS} / \mathrm{PP}=50 / 0.93)$, but with other positions in three one marker analyses (12S, 16S and 18S; Fig. 2). Concerning Perisphaerinae, Laxta sp., the only Australian individual sampled, was sister group to African Perisphaerinae (BS/PP $=32 / 0.93$ ), a result almost only found with the combined dataset (Fig. 2). 


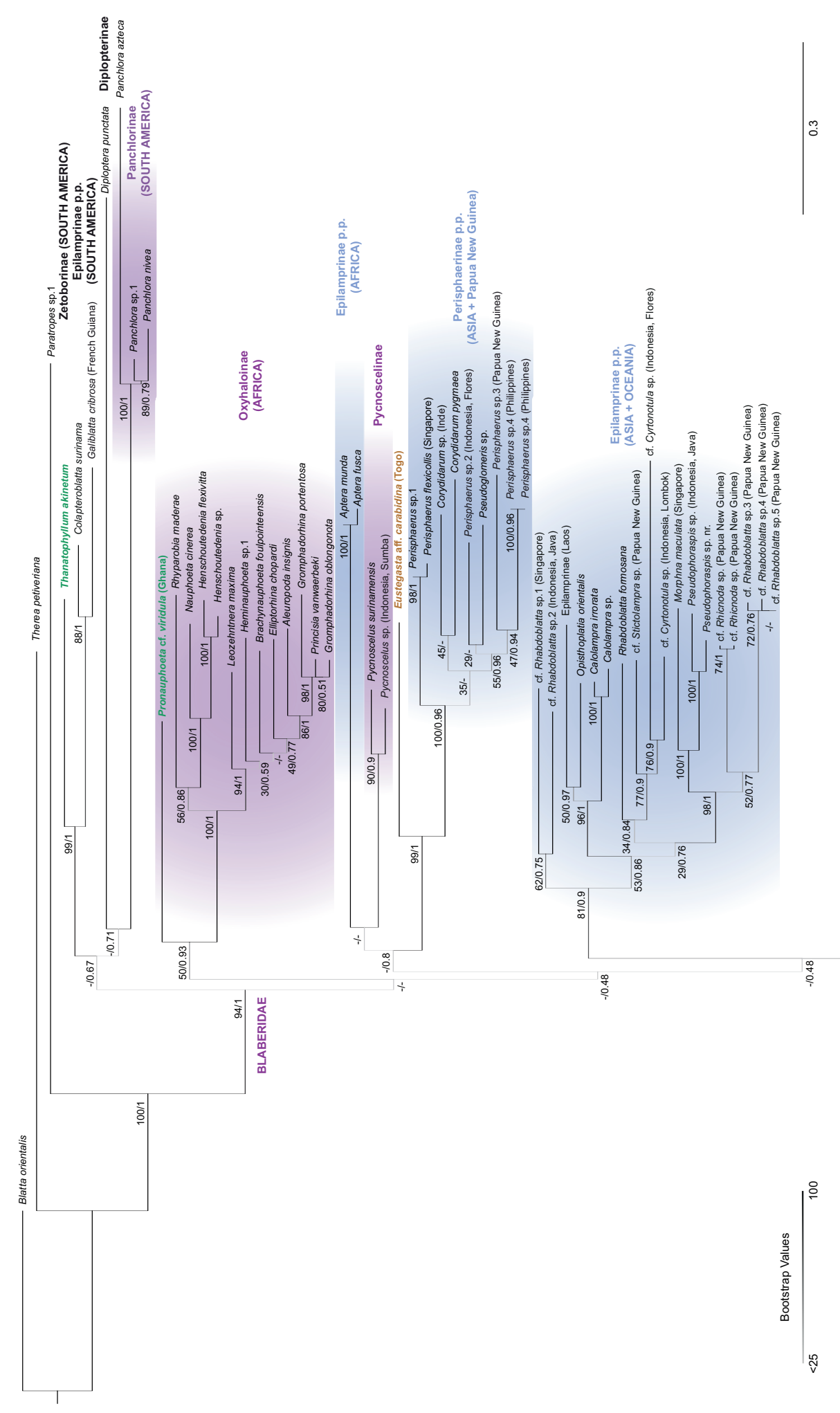

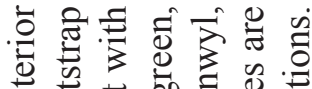

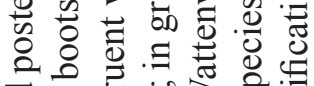

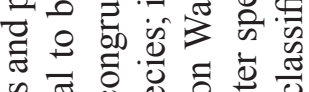

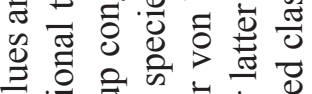

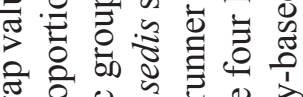

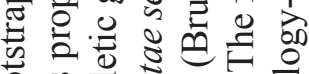

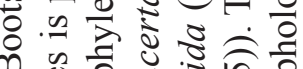

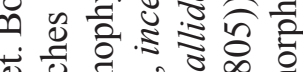
यें

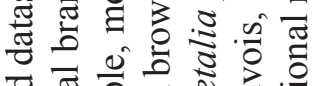

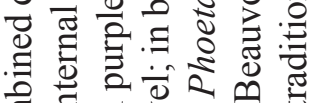

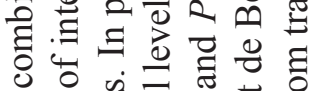

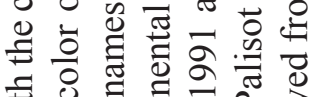

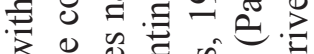

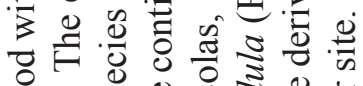

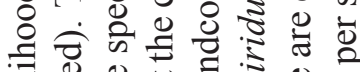

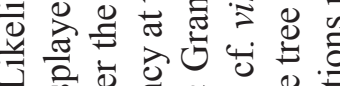

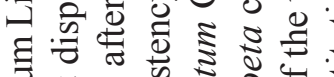

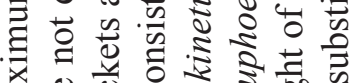

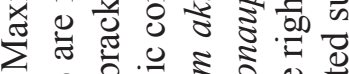

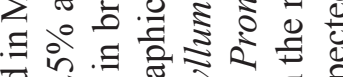
苋 N

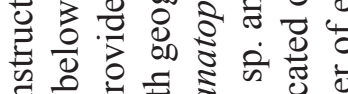

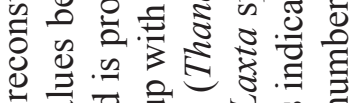
类

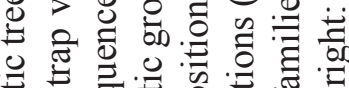
语离.

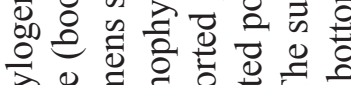

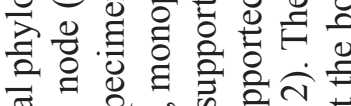

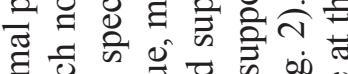

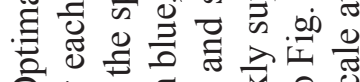

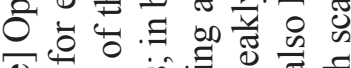

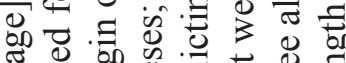
记 这.

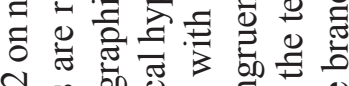
눈.

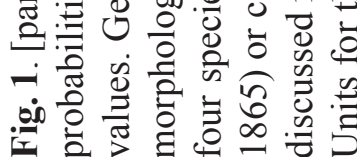




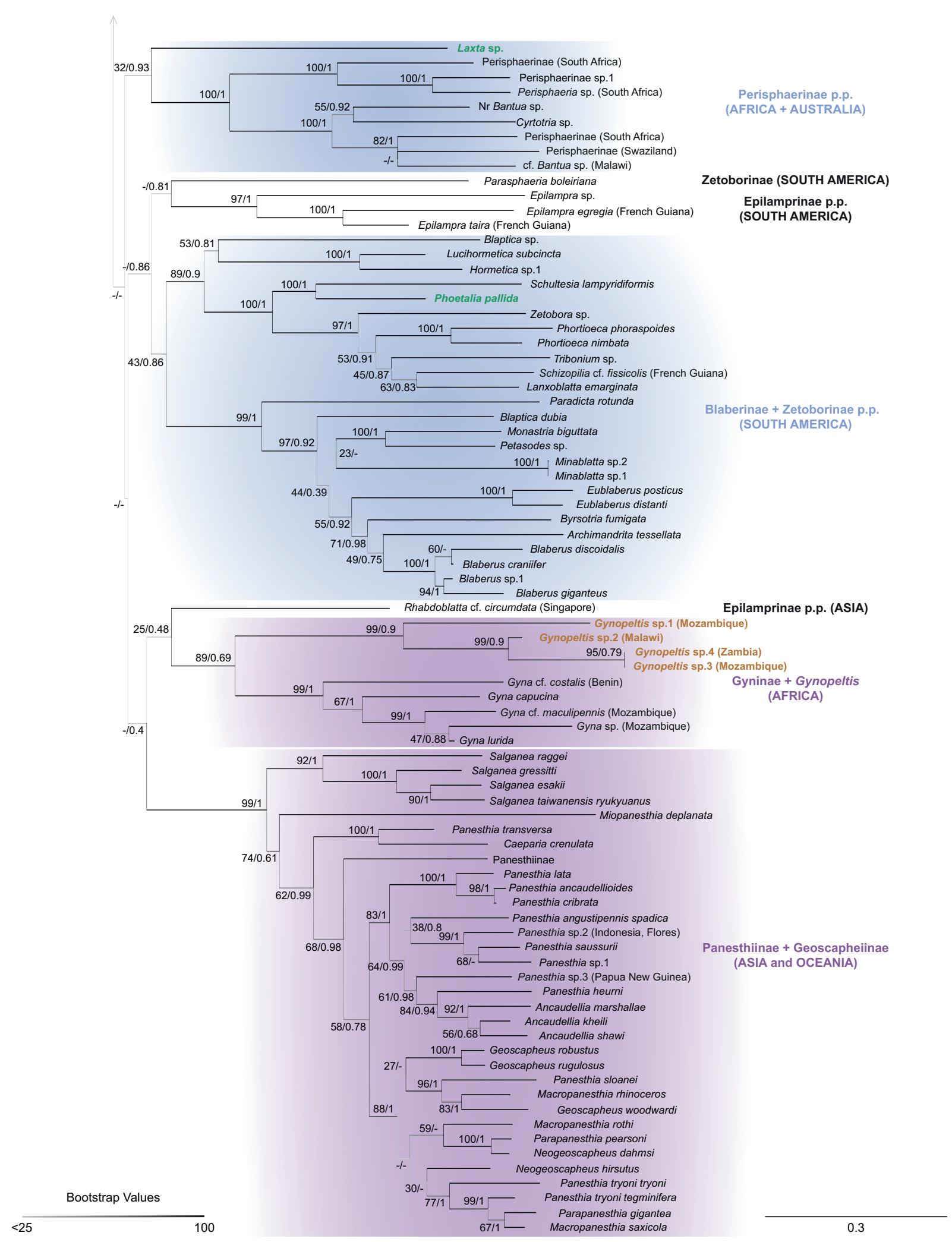

Fig. 1. Part 2. See legend on preceding page. 
Two incertae sedis genera were included in the analyses: Eustegasta aff. carabidina had Asian Perisphaerinae as its sister group (BS/PP $=99 / 1)$; Gynopeltis spp. were monophyletic (BS/PP = $99 / 0.9)$ and sister group to Gyninae (BS/PP $=89 / 0.69)$.

\section{Discussion}

Like for many different taxonomic groups, the traditional classification of Blaberidae relies mainly on morphological characters. Twelve subfamilies have been delimited so far, while 24 genera remain of unknown affinity. We sampled 11 of these subfamilies with molecular data to investigate the phylogenetic relationships of the family, which should be useful for classification and evolutionary studies in this cockroach family. We ended up with a broad-spectrum situation regarding congruence of our molecular phylogenetic hypothesis with the traditional morphology-based classification.

On the one side lie molecular hypotheses highly supported and congruent with morphology-based hypotheses. These unsurprising results have been suggested several times and concern the monophyly of Blaberidae, (Geoscapheinae + Panesthiinae) and Oxyhaloinae (Maekawa et al. 2003; Inward 2007; Pellens et al. 2007; Djernaes et al. 2012; Legendre et al. 2014, 2015). Likewise, a strong support was found, here and in previous studies, for Gyninae, Panchlorinae and Pycnoscelinae. It is worth noting though that for these subfamilies, only one genus was sampled, which is insufficient to test the monophyly of these subfamilies.

On the other side of the spectrum lie conflicting but poorly supported hypotheses. We do not discuss these results in depth because any conclusion about these groups would be premature. Indeed, given that deeper nodes were not supported, it is impossible to rule on the monophyletic status of the subfamily Perisphaerinae, for instance. Admittedly, African and Asian Perisphaerinae form two distinct and highly supported monophyletic groups. They were never found as sister groups, but none of their potential sister-group relationships were supported ( $\mathrm{BS}<35, \mathrm{PP}<0.73$ ), so assessing that they cannot be sister groups would be ill-advised. Similarly, Epilamprinae is split into four clades (and one isolated species) with some geographic consistency and with moderate to high support, but its sister-group relationships are weakly supported ( $\mathrm{BS}<25, \mathrm{PP}<0.73$ ). It is thus impossible to reach conclusions about these subfamilies with the molecular data at hand.

Thanatophyllum sister-species of Neotropical Epilamprinae

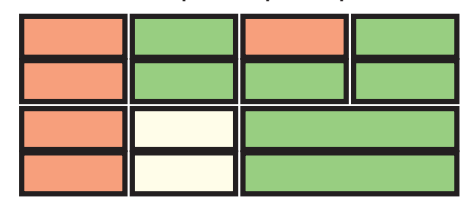

Pronauphoeta sister-species of Oxyhaloinae

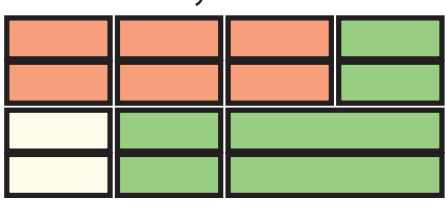

Phoetalia sister-species of Zetoborinae

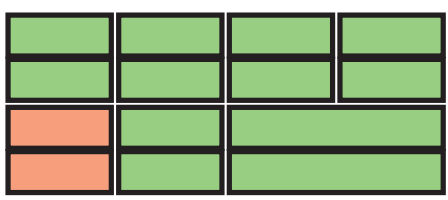

\begin{tabular}{|c|c|c|c|c|}
\hline $12 \mathrm{~S}$ & $16 \mathrm{~S}$ & $18 \mathrm{~S}$ & $28 \mathrm{~S}$ & $\mathrm{ML}$ \\
\hline $12 \mathrm{~S}$ & $16 \mathrm{~S}$ & $18 \mathrm{~S}$ & $28 \mathrm{~S}$ & $\mathrm{BI}$ \\
\hline $\mathrm{COI}$ & $\mathrm{BI}$ & COII & Combined & $\mathrm{ML}$ \\
\cline { 1 - 2 } & $\mathrm{MLI}$ & $\mathrm{COII}$ & Combined & $\mathrm{BI}$ \\
\hline
\end{tabular}

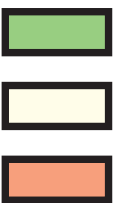

True

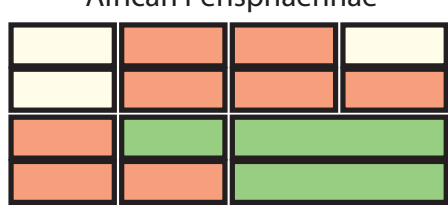

Untested or unresolved

False

Fig. 2. Conflicting results among different molecular markers. The phylogenetic relationships of four species are detailed for separate and combined analyses performed in Maximum Likelihood (ML) and Bayesian Inference (BI). Boxes colored as 'Untested or unresolved' refer to missing data and multifurcation, respectively. 
Interestingly, none of the molecular markers used here were informative enough to decipher the relationships among the major well supported blaberid clades, which remain poorly supported. This pattern does not seem to result from conflicting signals among molecular markers, because none of the separate analyses show robust deep relationships. Instead, it suggests that the molecular markers used are inefficient for deciphering these phylogenetic relationships. They appear uninformative for this period, which could suggest that a radiation occurred early on in the evolution of Blaberidae (probably during the Jurassic; Legendre et al. 2015), even though this remains to be demonstrated. Searching for new markers, as well as performing signal analyses, should help in making progress on this complicated issue (Whitfield \& Lockhart 2007). Conversely, it is worth noting that most of the clades found have a strong geographical coherence. We already mentioned Epilamprinae and Perisphaerinae but, interestingly, Geoscapheinae, which are Australian, are not monophyletic because Australian Panesthia are nested among them. With their pantropical distribution and their ancestry tracking back to the Mesozoic, Blaberidae can be a relevant model to investigate complex biogeographic scenarios. Nevertheless, the present analysis shows that, before elaborating on them, more robust knowledge of relationships of subfamilies is needed, an issue already raised before (Legendre et al. 2014).

Between the two extremities of this spectrum are arguably the most interesting situations: conflicting but highly supported results on one hand and congruent but poorly supported results on the other.

Phoetalia Stål, 1874 and Thanatophyllum Grandcolas, 1991 are two genera showing highly supported, but conflicting positions with morphology-based classifications, where they belong to the subfamilies Blaberinae and Zetoborinae, respectively. Here, on the basis of $5654 \mathrm{bp}$ belonging to five markers (COII is missing), Thanatophyllum akinetum was found to be the sister species of some Neotropical species of Epilamprinae. This relationship was found in half of the separate analyses performed (for the other analyses, T. akinetum was found as the sister species of Asian Epilamprinae, Perisphaerinae or Zetoborinae). At the moment of description, T. akinetum was placed within Zetoborinae (Grandcolas 1991), a position later supported in a cladistic study using 74 morphological characters and sampling 10 genera of Zetoborinae, 18 of Blaberinae, five of Gyninae and two of Diplopterinae (Grandcolas 1993). As for Phoetalia pallida, it was found nested within Blaberinae in Grandcolas (1993). Here it was found as the sister species of a species of Zetoborinae (Schultesia lampyridiformis), a result also found in five out of the six separate analyses. This disagreement between two studies with different taxon and character samplings does not allow us to decide which hypothesis, and thus which evolutionary scenario, should be favored. Blaberinae are notably characterized by male genitalia with spines on the prepuce (Roth 1970c). This character could be a synapomorphy of Blaberinae (including P. pallida), a striking convergence between P. pallida and Blaberinae (without P. pallida), or, depending on the phylogenetic structure of deeper nodes that remain to be deciphered, these spines could actually be a symplesiomorphy of a Neotropical clade comprising Blaberinae and most of the species of Zetoborinae. Solving these issues for these two species will require morphoanatomic work at the Blaberidae scale, building on previous studies (e.g., Grandcolas 1991, 1993; Roth 1970a, 1970b, 1970c), and/or in-depth signal analyses of molecular data (Thouzé et al. in prep.).

Two results are congruent with morphology-based classification but with low support in molecular analyses. Pronauphoeta sp. (Oxyhaloinae) and Laxta sp. (Australian Perisphaerinae) were found to be the sister species of all other Oxyhaloinae and African Perisphaerinae, respectively. Pronauphoeta Shelford, 1909 was first placed by Shelford (1909) as intermediate between Panchlora Burmeister, 1838 (Panchlorinae) and Nauphoeta Burmeister, 1838 (Oxyhaloinae) but was later suggested to be closer to Oxyhaloinae (Rehn 1932; Kumar 1975) than to Panchlorinae, a hypothesis supported here in the combined analyses and with the markers $28 \mathrm{~S}$ and COII (with the other markers, Pronauphaeta sp. was found as the sister species of some Epilamprinae, Perisphaerinae or in a much deeper position). At the tribe level, Pronauphoeta is of unknown affinity and, if its phylogenetic position were to be confirmed, 
would belong to a new tribe. As for Laxta Walker, 1868, Grandcolas (1997) revised the Perisphaerinae and inferred that it belonged to this subfamily given one external morphological character and four genitalic characters. Molecular data suggest that Laxta is closely related to African Perisphaerinae. Nevertheless, its phylogenetic position fluctuates in the different separate analyses, with, for instance, diverse deep positions within the tree based on 18S (ML and BI), 28S (BI), COI (BI) or COII (BI). This result is a remarkable example of disagreement between separate and combined analyses, where signal from the separate analyses disappears in the concatenated analysis (Sousa et al. 2013; Thiergart et al. 2014), a phenomenon that remains to be understood. Sampling other Australian species, notably from the genus Neolaxta Mackerras, 1968, will be necessary to confirm the phylogenetic position of Laxta and later suggest biogeographic scenarios for this subfamily, presently known from three continents (Asia, Africa and Oceania; Grandcolas 1997).

We provide here the first taxonomic affiliation based on molecular data for the incertae sedis genera Eustegasta and Gynopeltis. Gynopeltis was found, with strong support, as closely related to Gyninae. Other genera of Gyninae than Gyna must be sampled, however, to assess whether Gynopeltis belongs to the Gyninae or if another subfamily (Gynopeltinae) should be erected. Eustegasta has been suggested as belonging to the Perisphaerinae before it was removed from this subfamily (Roth 1973; Grandcolas 1997). Here this African genus, only documented for half of the marker, is found with strong support as a sister group to Asian Perisphaerinae.

By deciphering phylogenetic relationships in Blaberidae with six molecular markers, we ended up with phylogenetic hypotheses disagreeing, in part, with morphology-based classification. While some situations should be easily resolved with an increase in taxonomic sampling or a decrease in missing data (e.g., congruent results, but with weak support), others would require analyzing the phylogenetic signal of each molecular marker more in depth (e.g., the phylogenetic position of Laxta). Saturation plots and analyses of bias in nucleotide composition should be performed with phylogenetic informativeness and network analyses (Huson \& Bryant 2006; Townsend 2007; Philippe \& Roure 2011). Also, given the long branches in the putative sister group Pseudophyllodromiinae (Legendre et al. 2015) and the results of our preliminary analyses and of previous studies on the effect of outgroup choice on tree reconstruction in Dictyoptera (Ware et al. 2008; Djernaes et al. 2012), the impact of outgroup choice in the phylogenetics of Blaberidae should be investigated further. Analyzing these conflicting signals and their causes remains, however, a complicated task, so cockroach phylogenetics would above all else benefit from new appropriate markers that are now reachable with the development of next generation sequencing methods (Metzker 2010). Markers informative for the Jurassic period should probably be targeted first to investigate blaberid phylogenetics.

\section{Acknowledgments}

This work was supported by the network "Bibliothèque du Vivant" funded by the CNRS, and by the Muséum national d'Histoire naturelle, Paris (MNHN) under the grants "ATM - taxonomie moléculaire: DNA barcode et gestion durable des collections" and "ATM - biodiversité actuelle et fossile. Crises, stress, restaurations et panchronisme: le message systématique" to F.L. We thank Tony Robillard for his help in several field expeditions, for collecting specimens in Mozambique and for commenting on a previous version of this manuscript. We also thank the following people for providing specimens or for their assistance in the field: Leonid Anisyutkin (Zoological Institute of the Russian Academy of Sciences, Saint-Petersburg, Russia), Rudolf Meier (National University of Singapore, Singapore), Yayuk Suhardjono and Oscar Effendy (Museum of Bogor, Indonesia), Odette Morvan and Jean Cerda (French Guiana), Eric Guilbert (MNHN), and Henri-Pierre Aberlenc (Centre de Biologie pour la Gestion des Populations, Montpellier, France). We thank Roseli Pellens for commenting on a previous version of this manuscript. Some specimens were collected in Papua New Guinea during the expedition “Our Planet Reviewed Papua-New-Guinea 2012-2013" set up by Pro-Natura International, MNHN, the 
Institut de Recherche pour le Développement (IRD, France) in partnership with the Royal Belgian Institute of Natural Sciences, the New Guinea Binatang Research Center, the University of Papua New Guinea and the Divine Word University of Madang and with core funding from the Prince Albert II of Monaco Foundation, the Stavros Niarchos Foundation, the Total Foundation, the Fondation d'Entreprise EDF, the Fonds Pacifique, Spiecapag, Entrepose Contracting, the New Caledonia Government, the Reef Foundation and the Belgian National Lottery. The IBISCA expert network, the patron for this project, Prof. R.L. Kitching, and all other participants in this collective effort are thanked for their contribution. We also thank Gabien Colombini, Delia Dupré and Quentin Lefèvre for their help in molecular work, and two anonymous reviewers for their constructive criticisms. Bayesian analyses were performed with the cluster of UMS 2700 CNRS MNHN, Paris.

\section{References}

Baum D. \& Smith S.D. 2013. Tree Thinking. An Introduction to Phylogenetic Biology. Roberts \& Company, Greenwood Village, CO.

Baum D.A., Smith S.D. \& Donovan S.S.S. 2005. The tree-thinking challenge. Science 310: 979-980. https://doi.org/10.1126/science.1117727

Beccaloni G.W. 2014. Cockroach Species File Online. Version 5.0/5.0. Available from http://Cockroach. SpeciesFile.org [accessed 4 Jan. 2016].

Bergsten J. 2005. A review of long-branch attraction. Cladistics 21: 163-193. https://doi.org/10.1111/ j.1096-0031.2005.00059.x

Chiapella J., Kuhl J., Demaio P. \& Amarilla L. 2014. Fishing for significance in phylogenies: too many alternatives for the same outcome, or an appeal to journal editors. Ideas in Ecology and Evolution 7: 3-7. https://doi.org/10.4033/iee.2014.7.2.n

Costa J.T. 2006. The Other Insect Societies. Belknap Press of Harvard University Press, Cambridge, MA.

Darriba D., Taboada G.L., Doallo R., Posada D. 2012. jModelTest 2: more models, new heuristics and parallel computing. Nature Methods 9: 772-772. https://doi.org/10.1038/nmeth.2109

Djernæs M., Klass K.-D., Picker M.D. \& Damgaard J. 2012. Phylogeny of cockroaches (Insecta, Dictyoptera, Blattodea), with placement of aberrant taxa and exploration of out-group sampling. Systematic Entomology 37: 65-83. https://doi.org/10.1111/j.1365-3113.2011.00598.x

Edgar R.C. 2004. MUSCLE: multiple sequence alignment with high accuracy and high throughput. Nucleic Acids Research 32: 1792-1797. https://doi.org/10.1093/nar/gkh340

Gouy M., Guindon S. \& Gascuel O. 2010. SeaView version 4: A multiplatform graphical user interface for sequence alignment and phylogenetic tree building. Molecular Biology and Evolution 27: 221-224. https://doi.org/10.1093/molbev/msp259

Grandcolas P. 1991. Descriptions de nouvelles Zetoborinae guyanaises avec quelques remarques sur la sous-famille. Bulletin de la Société Entomologique de France 95: 241-246.

Grandcolas P. 1993. Monophylie et structure phylogénétique des [Blaberinae + Zetoborinae + Gyninae + Diplopterinae] (Dictyoptera: Blaberidae). Annales de la Société Entomologique de France 29: 195-222.

Grandcolas P. 1994. Phylogenetic systematics of the subfamily Polyphaginae, with the assignment of Cryptocercus Scudder, 1862 to this taxon (Blattaria, Blaberoidea, Polyphagidae). Systematic Entomology 19: 145-158. https://doi.org/10.1111/j.1365-3113.1994.tb00584.x

Grandcolas P. 1996. The phylogeny of cockroach families: a cladistic appraisal of morpho-anatomical data. Canadian Journal of Zoology 74: 508-527. https://doi.org/10.1139/z96-059 
Grandcolas P. 1997. The monophyly of the subfamily Perisphaeriinae (Dictyoptera: Blattaria: Blaberidae). Systematic Entomology 22: 123-130. https://doi.org/10.1046/j.1365-3113.1997.d01-28.x

Grandcolas P., Deleporte P. \& Desutter-Grandcolas L. 1994. Why to use phylogeny in evolutionary ecology? Acta Oecologica 15: 661-673.

Gregory T.R. 2008. Understanding evolutionary trees. Evolution: Education and Outreach 1: 121-137. https://doi.org/10.1007/s12052-008-0035-x

Huson D.H. \& Bryant D. 2006. Application of phylogenetic networks in evolutionary studies. Molecular Biology and Evolution 23: 254-267. https://doi.org/10.1093/molbev/msj030

Inward D., Beccaloni G. \& Eggleton P. 2007. Death of an order: a comprehensive molecular phylogenetic study confirms that termites are eusocial cockroaches. Biology Letters 3: 331-335. https:// doi.org/10.1098/rsbl.2007.0102

Klass K.-D. \& Meier R. 2006. A phylogenetic analysis of Dictyoptera (Insecta) based on morphological characters. Entomologische Abhandlungen 63: 3-50.

Kumar R. 1975. A review of the cockroaches of West Africa and the Congo Basin (Dictyoptera: Blattaria). Bulletin de l'Institut fondamental d'Afrique noire (Sciences naturelles) 37: 27-121.

Lanfear R., Calcott B., Ho S.Y.W. \& Guindon S. 2012. PartitionFinder: Combined selection of partitioning schemes and substitution models for phylogenetic analyses. Molecular Biology and Evolution 29: 16951701. https://doi.org/10.1093/molbev/mss020

Legendre F. 2007. Phylogénie et Évolution du Comportement social chez les Blattes et les Termites. PhD Thesis. Université Pierre et Marie Curie, Paris, France.

Legendre F., Whiting M.F., Bordereau C., Cancello E.M., Evans T.A. \& Grandcolas P. 2008. The phylogeny of termites (Dictyoptera: Isoptera) based on mitochondrial and nuclear markers: Implications for the evolution of the worker and pseudergate castes, and foraging behaviors. Molecular Phylogenetics and Evolution 48: 615-627. https://doi.org/10.1016/j.ympev.2008.04.017

Legendre F., D'Haese C., Deleporte P., Pellens R., Whiting M.F., Schliep K. \& Grandcolas P. 2014. The evolution of social behaviour in blaberid cockroaches with diverse habitats and social systems: phylogenetic analysis of behavioural sequences. Biological Journal of the Linnean Society 111: 58-77. https://doi.org/10.1111/bij.12199

Legendre F., Nel A., Svenson G.J., Robillard T., Pellens R. \& Grandcolas P. 2015. Phylogeny of Dictyoptera: Dating the origin of cockroaches, praying mantises and termites with molecular data and controlled fossil evidence. PLoS One 10: e130127. https://doi.org/10.1371/journal.pone.0130127

Lemmon A.R., Brown J.M., Stanger-Hall K. \& Lemmon E.M. 2009. The effect of ambiguous data on phylogenetic estimates obtained by maximum likelihood and Bayesian inference. Systematic Biology 58: 130-145. https://doi.org/10.1093/sysbio/syp017

Li X. 2007. Juvenile hormone and methyl farnesoate production in cockroach embryos in relation to dorsal closure and the reproductive modes of different species of cockroaches. Archives of Insect Biochemistry and Physiology 66: 159-168. https://doi.org/10.1002/arch.20207

Losos J.B., Arnold S.J., Bejerano G., Brodie E.D., Hibbett D., Hoekstra H.E., Mindell D.P., Monteiro A., Moritz C., Orr H.A., Petrov D.A., Renner S.S., Ricklefs R.E., Soltis P.S. \& Turner T.L. 2013. Evolutionary biology for the 21 st century. PLoS Biology 11: e1001466. https://doi.org/10.1371/journal.pbio.1001466

Maekawa K., Lo N., Rose H. \& Matsumoto T. 2003. The evolution of soil-burrowing cockroaches (Blattaria: Blaberidae) from wood-burrowing ancestors following an invasion of the latter from Asia into Australia. Proceedings of the Royal Society of London B 270: 1301-1307. https://doi.org/10.1098/ rspb.2003.2359 
McKittrick F.A. 1964. Evolutionary study of cockroaches. Cornell University Agricultural Experiment Station Memoir 389: 1-197.

Metzker M.L. 2010. Sequencing technologies - the next generation. Nature Reviews, Genetics 11: 3146. https://doi.org/10.1038/nrg2626

Nelson G.M., Quinn R.D., Bachmann R.J., Flannigan W.C., Ritzmann R.E. \& Watson J.T. 1997. Design and simulation of a cockroach-like hexapod robot. Proceedings of International Conference on Robotics and Automation 2: 1106-1111. https://doi.org/10.1109/robot.1997.614284

O'Hara R.J. 1997. Population thinking and tree thinking in systematics. Zoologica Scripta 26: 323-329. https://doi.org/10.1111/j.1463-6409.1997.tb00422.x

Omland K.E., Cook L.G. \& Crisp M.D. 2008. Tree thinking for all biology: the problem with reading phylogenies as ladders of progress. Bioessays 30: 854-867. https://doi.org/10.1002/bies.20794

Parr C.S., Guralnick R., Cellinese N. \& Page R.D.M. 2012. Evolutionary informatics: unifying knowledge about the diversity of life. Trends in Ecology and Evolution 27: 94-103. https://doi.org/10.1016/j. tree.2011.11.001

Pellens R., D’Haese C.A., Bellés X., Piulachs M.D., Legendre F., Wheeler W.C. \& Grandcolas P. 2007. The evolutionary transition from subsocial to eusocial behaviour in Dictyoptera: Phylogenetic evidence for modification of the "shift-in-dependent-care" hypothesis with a new subsocial cockroach. Molecular Phylogenetics and Evolution 43: 616-626. https://doi.org/10.1016/j.ympev.2006.12.017

Philippe H. \& Roure B. 2011. Difficult phylogenetic questions: more data, maybe; better methods, certainly. BMC Biology 9: e91. https://doi.org/10.1186/1741-7007-9-91

Rambaut A., Suchard M.A., Xie D. \& Drummond A.J. 2014. Tracer 1.6. Available from http://beast.bio. ed.ac.uk/Tracer [accessed 6 Sept. 2015].

Rehn J.A.G. 1932. African and Malagasy Blattidae (Orthoptera), part II. Proceedings of the Academy of Natural Sciences of Philadelphia 84: 405-511.

Ronquist F. \& Huelsenbeck J.P. 2003. MrBayes 3: Bayesian phylogenetic inference under mixed models. Bioinformatics 19: 1572-1574. https://doi.org/10.1093/bioinformatics/btg180

Roth L.M. 1970a. The male genitalia of Blattaria. III. Blaberidae: Zetoborinae. Psyche 77: 217-236. https://doi.org/10.1155/1970/14743

Roth L.M. 1970b. The male genitalia of Blattaria. IV. Blaberidae: Blaberinae. Psyche 77: 308-342. https://doi.org/10.1155/1970/72938

Roth L.M. 1970c. The male genitalia of Blattaria. V. Epilampra spp. (Blaberidae: Epilamprinae). Psyche 77: 436-486. https://doi.org/10.1155/1970/46805

Roth L.M. 1973. The male genitalia of Blattaria. XI. Perisphaeriinae. Psyche 80: 305-348. https://doi. org/10.1155/1973/48938

Roth L.M. 2003. Systematics and phylogeny of cockroaches (Dictyoptera: Blattaria). Oriental Insects 37: 1-186. https://doi.org/10.1080/00305316.2003.10417344

Roth L.M. \& Willis E.R. 1954. The reproduction of cockroaches. Smithsonian Miscellaneous Collections 122: $1-49$.

Roure B., Baurain D. \& Philippe H. 2013. Impact of missing data on phylogenies inferred from empirical phylogenomic data sets. Molecular Biology and Evolution 30: 197-214. https://doi.org/10.1093/molbev/ $\underline{\operatorname{mss} 208}$ 
De Saussure H. 1864. Orthoptères de l'Amérique moyenne. In: De Saussure H. (ed.) Mémoires pour servir à l'Histoire naturelle du Mexique, des Antilles et des Étas-Unis, vol. 1: 1-279. Bamboz \& Schuchardt, Geneva.

Shelford R. 1909. Descriptions of some new genera and species of Blattidae (Orth.). Deutsche Entomologische Zeitschrift 5: 611-624. Available from http://biodiversitylibrary.org/page/33103293 [accessed 20 Feb. 2017].

Sousa F.L., Thiergart T., Landan G., Nelson-Sathi S., Pereira I. a C., Allen J.F., Lane N. \& Martin W.F. 2013. Early bioenergetic evolution. Philosophical Transactions of the Royal Society of London B 368: e20130088. https://doi.org/10.1098/rstb.2013.0088

Stamatakis A. 2014. RAxML version 8: a tool for phylogenetic analysis and post-analysis of large phylogenies. Bioinformatics 30: 1312-1313. https://doi.org/10.1093/bioinformatics/btu033

Thiergart T., Landan G. \& Martin W.F. 2014. Concatenated alignments and the case of the disappearing tree. BMC Evolutionary Biology 14: 266-277. https://doi.org/10.1186/s12862-014-0266-0

Townsend J.P. 2007. Profiling phylogenetic informativeness. Systematic Biology 56: 222-231. https:// doi.org/10.1080/10635150701311362

Vaidya G., Lohman D.J. \& Meier R. 2011. SequenceMatrix: concatenation software for the fast assembly of multi-gene datasets with character set and codon information. Cladistics 27: 171-180. https://doi. org/10.1111/j.1096-0031.2010.00329.x

Ware J.L., Litman J., Klass K.-D. \& Spearman L.A. 2008. Relationships among the major lineages of Dictyoptera: the effect of outgroup selection on dictyopteran tree topology. Systematic Entomology 33: 429-450. https://doi.org/10.1111/j.1365-3113.2008.00424.x

Wheeler W.C. 1990. Nucleic acid sequence phylogeny and random outgroups. Cladistics 6: 363-367. https://doi.org/10.1111/j.1096-0031.1990.tb00550.x

Whitfield J.B. \& Lockhart P.J. 2007. Deciphering ancient rapid radiations. Trends in Ecology and Evolution 22: 258-265. https://doi.org/10.1016/j.tree.2007.01.012

Manuscript received: 29 January 2016

Manuscript accepted: 31 January 2017

Published on: 3 March 2017

Guest editors: Line Le Gall, Frédéric Delsuc, Stéphane Hourdez, Guillaume Lecointre

and Jean-Yves Rasplus

Desk editor: Danny Eibye-Jacobsen

Printed versions of all papers are also deposited in the libraries of the institutes that are members of the EJT consortium: Muséum national d'Histoire naturelle, Paris, France; Botanic Garden Meise, Belgium; Royal Museum for Central Africa, Tervuren, Belgium; Natural History Museum, London, United Kingdom; Royal Belgian Institute of Natural Sciences, Brussels, Belgium; Natural History Museum of Denmark, Copenhagen, Denmark; Naturalis Biodiversity Center, Leiden, the Netherlands.

Legend for Supplementary file. List of specimens used in this study, with information about the completion of our dataset. A color code is used to show the traditional taxonomic affiliation of the species sampled. 